\title{
Neurological Complications of Hypothyroidism
}

\author{
Hande Turker ${ }^{1}$, Cuneyt Turker ${ }^{2}$ and Nilgun Cengiz ${ }^{1}$ \\ ${ }^{1}$ Ondokuzmayis University, School Of Medicine, \\ Department of Neurology, Samsun, \\ ${ }^{2}$ Gazi State Hospital, Clinic of Internal Medicine, Samsun \\ Turkey
}

\section{Introduction}

Hypothyroidism is the most common pathological hormone deficiency (Roberts et al, 2004). The variety of end-organ effects and wide range of disease severity-from entirely asymptomatic individuals to patients in coma with multisystem failure-can make hypothyroidism an elusive clinical entity (Roberts et al, 2004). Hypothyroidism was first described in the 19 th century.

Impaired memory, slowed mental processing, depression, nerve entrapment syndromes, ataxia, muscle weakness and muscle cramps are the most common neurological symptoms which may be caused by hypothyroidism (Roberts et al, 2004). Disorders of the thyroid gland are among the most common endocrine maladies. Hypothyroidism is the most prevalent form of thyroid disease and symptoms may include memory and learning impairment, depression, psychotic behaviour, retarded locomotor ability, somnolence, progressive intellectual deterioration and, in extreme cases, coma (Anderson, 2001; Smith et al., 2002). Since the thyroid hormones dramatically affect the maturation of specific neuronal populations, the absence of these hormones during the period of active neurogenesis leads to irreversible mental retardation and is accompanied by multiple morphological alterations in the brain (Smith et al., 2002).

\section{Central nervous system involvement due to hypothyroıdısm}

Disruption of thyroid hormone production during fetal and early neonatal development leads to a suite of permanent deficits in intelligence and sensorimotor function in humans (Dong et al, 2005).

Clinical hypothyroidism indicates a pervasive deficit in thyroid hormone actions, including modulation of calorigenesis and oxygen consumption in most tissues and additional organspecific effects (Roberts et al, Lancet).

Brain-derived neurotrophic factor (BDNF) is a neurotrophin critical for many developmental and physiological aspects of CNS function. Severe hypothyroidism in the 
early neonatal period results in developmental and cognitive impairments and reductions in mRNA and protein expression of BDNF in a number of brain regions (Lasley et al., 2011).

The action of thyroid hormones (THs) in the brain is strictly regulated, since these hormones play a crucial role in the development and physiological functioning of the central nervous system (CNS) (Ahmed et al., 2008).

Transient reductions in thyroid hormone during critical periods of brain development can have devastating and irreversible effects on neurological function (Gilbert et al, 2004). The hippocampus is a brain region sensitive to thyroid hormones and is a necessary substrate for some forms of learning and memory. Subregions within the hippocampus display distinct ontogenetic profiles and have shown differential vulnerability to some indices of thyrotoxic insult. Synaptic function can be readily assessed in the hippocampus, yet little information exists on the consequences of early thyroid hormone insufficiency on the neurophysiological integrity of this structure (Gilbert et al, 2004).

Thyroid hormone deficiency during the critical period of neural differentiation produces permanent and severe alterations in the morphology and function of the nervous system leading to cretinism. Perinatal hypothyroidism results in permanent alterations of hippocampal synaptic functions in adult rats consequently causing learning and memory impairment (Calloni et al., 2005).

It has been established that both L-thyroxine (T4) and L-3,5,39-triiodothyronine (T3) are present in the adult brain. Moreover, the enzyme deiodinase type II, which is mainly responsible for converting inactive T4 to active form T3, is also present in glial and neural cells (Calza et al., 1997).

Finally, receptors for thyroid hormone T3 are localized in nuclei of glial cells and neurons in different brain areas (Calza et al., 1997).

Thyroid hormone is essential for proper development of the mammalian CNS. Previous studies have documented a decrease in the ability of neonatal hypothyroid animals to learn and to habituate to maze tests and an increase in spontaneous activity (Darbra et al, 2003). On the other hand some observers stated that children with hypothyroidism had no apparent specific impediments to learning unrelated to intelligence (England Congenital Hypothyroidism Collaborative New, 1990).

Cognitive neurological symptoms are common in myxoedema, in particular a general slowing of cognitive functions with memory impairment and apathy. This may progress insidiously to a global cognitive impairment of dementia. Appropriate treatment with replacement therapy will sometimes improve mental changes,though they are frequently only partially reversible (Osterweil et al., 1992). The longer the condition remains undiagnosed, the worse the outcome (Dennis et al., 2005).

The in vitro studies demonstrate that adult hippocampal progenitors exhibit enhanced proliferation, survival and glial differentiation in response to thyroid hormone. These results support a role for thyroid hormone in the regulation of adult hippocampal neurogenesis and raise the possibility that altered neurogenesis may contribute to the cognitive and behavioral deficits associated with adult-onset hypothyroidism (Desouzo et al., 2005). 
According to a study by Bhanja et al., the results suggest that the antioxidant defence system of the developing cerebellum is sensitive to thyroid hormone deficiency and consequent alterations in oxidative stress status may play a role in regulation of cell proliferation of the cerebellum during neonatal brain development (Bhanja et al.,2010).

In vitro, THs (thyroid hormones) have been reported to modulate astrocyte morphology, differentiation, and proliferation and to regulate extracellular matrix (ECM) organization and synthesis (Dezonne et al, 2009). In vivo, THs regulate radial gliaastrocyte transition and the vimentin-GFAP (glial fibrillary acidic protein) switch, a hallmark of astrocyte differentiation, in the basal forebrain and hippocampus (Dezonne et al., 2009).

Prompt treatment of maternal hypothyroidism, identified by increased TSH, is being advocated to mitigate a negative effect on the woman and her child. However, even a moderate transient period of maternal hypothyroxinemia at the beginning of rat neurogenesis disrupts neuronal migration into cortical layers. These findings reinforce the epidemiological evidence that early maternal hypothyroxinemia - when neuronal migratory waves are starting - is potentially damaging for the child. Detection of an inappropiate first trimester FT4 surge that may not result in increased TSH, may be crucial for the prevention of learning disabilities in a significant number of unborn children (Escobar et al., 2004)

The positive effects of thyroid hormones on cognition has led to some new therapeutic approaches regarding the usage of these hormones in dementia therapy. The results of a study by $\mathrm{Fu}$ et al, indicate that the use of $\mathrm{TH}$ has some therapeutic potential in AD (Fu et al.,2009).

The congenital absence of thyroid hormone alters neuronal firing behavior during early stages of the development in rat. These changes in neuronal discharge are related to their spike ADP, which is clearly involved in the burst-firing behavior in developing CA1 pyramidal neurons (Sanchez Alonso et al., 2010; Chen et al., 2005).

The relationship between the thyroid axis and psychiatric symptoms and disease is well established. In particular, clinical hypothyroidism leads to depressive symptoms which resolve with replacement therapy. The relationship between alterations of thyroid function and primary major depression is more complex. While various abnormalities of the thyroid axis have been identified, none is specific for depression and there is no clear evidence that thyroid hypofunction is a significant etiological factor in major depression. The literature on thyroid hormone treatment of depression, particularly treatment-resistant major depression, is highly promising and warrants further investigation. Greater understanding about thyroid-brain relationships may yield important information about the etiology of major mood disorders (Joffe et al., 2009).

It is already known that hypothyroidism may alter the evoked potentials. Since 1990s some studies were performed to show this.

In order to detect the dysfunction of central and peripheral nervous systems among rats with varied duration of hypothyroidism and to elucidate the pattern of recovery after thyroxine replacement, a series of BAEP (Brainstem auditory evoked potentials) and PNCS (Peripheral Nerve Conduction Study) were conducted and compared with age-matched controls. BAEP and PNCS were performed in three groups of hypothyroid animals 1, 3 and 5 months after thyroidectomy, respectively. Following initial electrophysiological 
assessment, thyroxine replacement was administered to each group of hypothyroid rats, and BAEP and PNCS were performed at two month intervals, up to two successive normal studies, or six months after the initiation of therapy, whichever came first. For BAEP, prolonged I-V interpeak latency was the most consistent abnormal finding in all groups of hypothyroid rats, and longer hypothyroid states correlated well with more severe central conduction disorder (Lai et al., 1997).

Nevertheless, these abnormalities usually returned to normal after thyroxine replacement if the duration of hypothyroidism was less than 5 months. Regarding PNCS, all groups of thyroidectomized rats showed normal conduction before and after thyroxine therapy. This study indicated that, in rats: (1) the peripheral nervous system seemed to be more resistant to hypothyroidism than the central nervous system, or (2) the pathogenesis of central and peripheral nerve dysfunction in hypothyroid rats might occur through different mechanisms (Lai et al., 1997).

After thyroxine replacement, the central conduction dysfunction usually returned to normal if the hypothyroid state was not more than 5 months in duration. However, when hypothyroid state persisted over 7 months or more, there would be an incomplete recovery for central conduction disorder. This study brought out the concept of 'therapeutic window' in reversing the central nervous dysfunction caused by hypothyroidism in adult rats (Lai et al, 2000).

According to a study by MacNabb et al., the results suggested that congenital hypothyroidism impaired learning when a discrimination between correct and incorrect operations is made available (Mac Nabb et al., 1999).

Hypothyroidism was also linked to some degenerative diseases of the brain. According to a study performed by Munhoz et al., thyroid function should be assessed in parkinson patients showing worsening of symptoms that cannot be explained by disease progression or resistance to therapy adjustment (Munhoz et al., 2004).

Hypothyroidism during Iodine-therapy is associated with clinically relevant cognitive dysfunctions, especially with effortful attention demanding tasks (Munte et al.,2004).

Processes under the control of TH (thyroid hormones) range from learning and anxiety-like behaviour to sensory function. At the cellular level,TH controls events as diverse as axonal outgrowth, hippocampal synaptic activity and the patterning of opsin photopigments necessary for colour vision. Overall, TH coordinates this variety of events in both central and sensory systems to promote the function of the nervous system as a complete entity (Nunez et al., 2008).

Age at onset of hypothyroidism is suggested to be an important factor for the memory impairment induced by hypothyroidism. In a study performed by Tong et al.,the 2-monthold hypothyroid mice had significantly impaired abilities in both the olfactory discrimination and the spatial cognitive tasks relative to the 2-month-old controls. The 8month-old hypothyroid mice had only impaired ability in the spatial cognitive task relative to the same age controls. The 15-month-old hypothyroid mice retained these cognitive abilities relative to the same age controls. These results suggested that adult-onset hypothyroidism could induce an age- and task-dependent impairment of memory in female KM mice (Tong et al.,2007). 
Thyroid hormone deficiency has profound effects on the brain during development and less marked effects on the adult brain. These effects are considered to be the result of the direct regulation of specific target genes by thyroid hormone. Previous studies have shown that the expression of the neuronal gene RC3, encoding a 78-amino-acid calmodulin-binding protein kinase $\mathrm{C}$ substrate, is under the influence of thyroid hormone in vivo (Piosik et al, 1997). In their study Piosik et al., investigated the role of thyroid hormone in RC3 mRNA expression at earlier stages of fetal development and in mature goats using in situ hybridization. Their data indicated that in both fetal and adult goats thyroid hormone, at least partly, affected the expression of RC3 mRNA in the striatum and not the cerebral cortex (Piosik et al, 1997).

It was shown that in the rat cerebellar cortex, the expression of mabN210-immunoreactivity in basket cell axons was severely suppressed in hypothyroidism while neurofilament antigen expression in other cerebellar axons seemed not to require thyroid hormones (Plioplys et al., 1986). In hypothyroid rats there is a marked supression of mabN210-immunoreactivity in the cerebral cortex and corpus callosum and, to a lesser extent, there is a reduction in staining in the internal capsule. By contrast, hypothyroidism did not reduce mabN210-immunoreactivity in the lateral olfactory tract or the stria medullaris. In rats, serum thyroid hormone starts to rise to adult levels on postnatal day 4. It appears that axons that have attained their mature distribution prior to the onset of thyroid hormone expression are not affected by hypothyroidism whereas mabN210-immunoreactivity is suppressed in those axonal tracts that reach a mature distribution after P4(Plioplys et al., 1986).

Cerebellar development on the postnatal period is mainly characterized by cellular proliferation in the external granular layer (EGL) followed by migration of granular cells in the molecular layer through the Bergmann glia (BG) fibers in order to form the granular layer in the adult. All these events are drastically affected by thyroid hormones (TH), actions of which are mainly mediated by alpha (TRa) and beta (TR $\beta$ ) nuclear receptor isoforms (Portello et al., 2010).

Portello et al., analyzed the effects of a natural human mutation (337T) in the TR $\beta$ locus, which impaired T3 binding to its receptor, on the mouse cerebellum ontogenesis. They reported that target inactivation of TR $\beta-\mathrm{TH}$ binding led to a smaller cerebellum area characterized by impaired lamination and foliation. Further, TR $\beta$ mutant mice presented severe deficits in proliferation of granular precursors, arborization of Purkinje cells and organization of BG fibers. They reported that their data suggested that the action of $\mathrm{TH}$ via TR $\beta$ regulated important events of cerebellar ontogenesis contributing to a better understanding of some neuroendocrine disorders. Further, their data correlated TR $\beta$ with cerebellar foliation, and provided, for the first time, evidence of a receptor-mediated mechanism underlying TH actions on this event (Portello et al., 2010).

Hypothyroidism has numerous effects on brain. It produces a hypometabolic state. Hypometabolic state following hypothermia is known to protect tissues from ischemic injury. A study by Rastogi et al., provided evidence that hypothyroidism made neuronal tissue less vulnerable to severe ischemic insult (Rastogi et al., 2006).

In a study by Rovet et al.,sixty-nine children with congenital hypothyroidism detected through thyroid screening were compared with 39 unaffected siblings for cognitive and 
temperamental characteristics. Intelligence test results revealed: (1) IQs of hypothyroid children were normal but lower than siblings; (2) hypothyroid children were lower than siblings in gross motor and perceptual performance abilities; (3) athyrotic children had lower IQs than those with ectopic thyroids, goiter, or hypoplastic disease; (4) athyrotic, hypoplastic, and ectopic thyroid children had lower performance than verbal IQs, but there was no scale difference for those with goiter; (5) deficits differed according to test age; and (6) age of onset of treatment was not related to IQ or pattern of deficit. Temperament test findings revealed: (1) no increase in difficult or slow-to-warm-up children, (2) lower ratings were found for hypothyroid children than siblings on approach/withdrawal and persistence scales, and (3) higher rating was given for athyrotic children than those with goiter (Rovet et al, 1984).

In a study performed by the same authors, hearing loss and its functional consequences were evaluated retrospectively in children with congenital hypothyroidism. Hearing impaired children differed from children with normal hearing in age of treatment onset (22 vs 14 days) but not disease severity or duration. A comparison of language and auditory processing skills at ages 3,5, and 7 years revealed that early speech was delayed in hearing impaired children, whereas deficits persisted in later receptive language and auditory discrimination skills. Comparing hearing impaired children and children with normal hearing with matched control subjects at grade 3 showed that hearing impaired children were poorer readers because of less adequate phonologic processing skills (Rovet et al, 1996).

In another study that evaluated the influence of thyroid function on the activity and exploratory behaviour of rats, chronic hyperthyroidism produced a significant increase in activity, but did not affect exploration. On the other hand, hypothyroidism did not affect activity, but did increase exploration. This increase in exploration was observed in activity independent behavioural parameters, such as head dipping and glancing (Sala-Roca et al., 2002).

In a study by Sawin et al., the effects of hypothyroidism on development of cholinergic system in brain regions (prefrontal cortex and hippocampus) were evaluated by measuring choline acetyltransferase (ChAT) activity and hemicholinium-3 binding to the high-affinity choline transporter (Sawin et al., 1998). The results suggested that alterations of cholinergic system caused by perinatal hypothyroidism were associated with neurobehavioral deficits at weaning, and these developmental deviations might cause permanent impairment of cognitive function despite recovery from the hormonal imbalance at adult ages (Sawin et al., 1998).

The association of ocular abnormalities with thyroid disorders is well-known, wherein iodine plays an important role. Iodine deficiency and excess can both lead to abnormalities of thyroid function.

Neuromuscular ocular dysfunction in hypothyroidism includes ptosis, ophthalmoplegia, myokymia, cranial nerve dysfunction and cosmetic changes (Seah et al., 2009).

In addition to their role in cellular metabolic activity, thyroid hormones also regulate neural development. Central nervous system is dependent on thyroid hormones for normal maturation and function. Specifically there appears to be extensive inter-reliance between 
thyroid hormones and acetylcholine, nerve growth factor and hippocampal function (Smith JW et al, 2002).

Thyroid abnormalities have been associated with attention deficit/hyperactivity disorder (ADHD) and with other childhood psychiatric disorders. In a study designed to determine the relationships between thyroid hormone concentrations, neurocognitive functioning, and psychiatric diagnosis in children; thyroxine concentrations were associated with mood symptoms and unusual behaviors, and were less strongly related to attentional functioning. Thyroxine concentrations were not related to hyperactivity (Stein MA et al., 2002).

Insufficiency of thyroid hormones in the adulthood causes a wide range of cognitive dysfunctions, including deficits in learning and memory. In a study that investigated whether adult-onset hypothyroidism would alter synaptic functions in the dorsal hippocampo-medial prefrontal cortex (mPFC) pathway, a neural pathway important for learning and memory, the results suggested that alterations in synaptic plasticity of the dorsal hippocampo-mPFC pathway might contribute to understanding basic mechanisms underlying learning and memory deficits associated with adult-onset hypothyroidism (Sui et al., 2006).

Adult-onset hypothyroidism is associated with neurological changes such as cognitive dysfunction and impaired learning, which may be related to alterations of synaptic plasticity. In a study designed to investigate the consequence of adult-onset hypothyroidism on thyroid-mediated transcription events in striatal synaptic plasticity, and the effect of triiodothyronine (T3) replacement; the authors suggested that thyroid hormone modulation had a major impact on striatal synaptic plasticity of adult mice which produced in turn motor behavior modifications (Vallortigara et al.,2007).

Thyroid hormone action on brain development is essentially exerted through regulation of the expression rate of a number of genes some of which have been identified in the past 10 years (Vargiu et al., 2001).

Attention-deficit hyperactivity disorder (ADHD) is thought to have a biologic basis, but the precise cause is unknown. It is one of the neurodevelopmental abnormalities frequently observed in children with generalized resistance to thyroid hormone (GRTH), suggesting that thyroid abnormalities may be related to ADHD. According to a study by Weiss et al., the prevalence of thyroid abnormalities is higher (5.4\%) in children with ADHD than in the normal population $(<1 \%)$ (Weiss et al., 1993).

According to a study to assess the impact on neonatal neurobehavioral development of methimazole (MMI)-induced in-utero hypothyroxinemia and of correction by maternal-fetal thyroxine $\left(\mathrm{T}_{4}\right)$ transfer in the rat by Weller et al., prenatal $\mathrm{T}_{4}$ treatment resulted in correction of MMI-induced delayed appearance of three different reflexes. Body-weight gain of treated pups was similar to that of controls and more rapid than development of rats treated with MMI-alone. $\mathrm{T}_{4}$ treatment did not prevent, however, MMI-induced delay in maturation of physiological landmarks (e.g. ear opening). The authors suggested that at least a portion of the developmental delay resulting from prenatal (maternal) MMI administration might be reversed by maternal-fetal transfer of $\mathrm{T}_{4}$ administered to the gravid dam (Weller et al, 1996).

Thyroid hormone insufficiency leads to impaired neurogenesis, behavioral alterations and cognitive deficits. Thyroid hormone receptors, expressed in brain regions involved in these 
behaviors, mediate the effects of thyroid hormone deficiency or excess. Thyroid hormoneregulated genes potentially responsible for the learning deficit found in TR_o/o mice include GR, RC3 and GAP-43 (Wilcoxon et al., 2007).

Developmental thyroid hormone $(\mathrm{TH})$ deficiency leads to mental retardation and neurological deficits in humans. According to a study by Zamoner et al., the thyroid status could modulate the integrity of neuronal cytoskeleton acting on the endogenous NFassociated phosphorylating system and that such effect could be related to glutamateinduced excitotoxicity (Zamoner et al., 2008).

Myxoedema coma is a complication of long-standing untreated hypothyroidism. The term is largely a misnomer since most patients are not comatose. This condition is characterised by marked impairment of the central nervous system and of cardiovascular function (Jansen et al.,2006).

Hashimoto encephalopathy, also known as steroid-responsive encephalopathy associated with autoimmune thyroiditis, is a potentially fatal condition associated with a presentation of myoclonus, altered conscious state, strokelike episodes, rapid cognitive decline, and neuropsychiatric symptoms, including psychosis, hallucinations, and abulia.It is an important differential diagnosis of rapidly progressive dementia. It is also an important cause of potentially reversible dementia because with prompt and appropriate treatment its symptoms can be completely reversed. Controversially, Hashimoto encephalopathy can present in the absence of associated thyroid function abnormalities, even though it is associated with high titers of antithyroid peroxidase and antithyroglobulin antibodies. (Brodtmann et al.,, 2009)

\section{Effects of hypothyroidism on the peripheral nervous system}

The connection between hypothyroidism and polyneuropathy was known thouroughly even in the 70s. In a case study by Shirabe et al., it was suggested that myxoedematous polyneuropathy might be intrinsic neuropathy due to metabolic disorder of Schwann cells related to hypothyroidism, resulting in segmental demyelination, not merely compressive neuropathy due to mucinous deposits in the peripheral nerves (Shirabe et al.,1975). More case studies followed in 80s also (Martin et al., 1983).

Muscle involvement in a variety of forms is a common complication of adult-onset hypothyroidism. Hypothyroid myopathy spans a clinical spectrum that includes a number of different manifestations. The reported prevalence of hypothyroid myopathy symptoms and signs is variable. In a prospective cohort study, $79 \%$ of adult patients with hypothyroidism had muscle complaints (myalgias, cramps or weakness). Asymptomatic CK elevation has been reported to occur in $37 \%$ to $60 \%$ of hypothyroid patients . Other significant manifestations associated with hypothyroidism include: myalgias, severe muscle weakness, polymyositis-like syndrome, rhabdomyolysis, and acute compartment syndrome (ACS). Rhabdomyolysis after withdrawal of thyroid hormone in a patient with papillary thyroid cancer has been described previously (Ramadhan et al., 2009).

The frequency of myopathy in hypothyroidism ranges from 30 to $80 \%$. The major symptoms related are weakness, muscular cramps and myalgia. The pseudohyperthrophic form is called Hoffman's syndrome. The electrophysiological study reveals myopathy, neuropathy 
or mixed pattern. Laboratorial investigation generally shows increased levels of muscle enzymes and low serum thyroid hormones, with thyrotrophic-stimulating hormone (TSH) elevated. The treatment consists in hormone replacement and the prognosis is good in most of the cases (Vasconcellos LFR et al.,2003).

In a study performed by Magri et al., intraepidermal nerve fiber density reduction was evaluated as a marker of preclinical asymptomatic small-fiber sensory neuropathy in hypothyroid patients. Their findings suggested that a considerable number of untreated hypothyroid patients may have preclinical asymptomatic small-fiber sensory neuropathy (Magri et al., 2010).

According to a study by Salvi et al., visual evoked potentials in patients with thyroidassociated ophthalmopathy (TAO) identify asymptomatic optic nerve involvement. The authors observed a prolongation of the latency of the evoked cortical response in patients with TAO without subjective visual complaints and without optic nerve compression. They reported that the study of visual evoked potentials in TAO is complementary to the study of the visual field in identifying early optic nerve dysfunction in the absence of decreased visual acuity (Salvi et al, 1997).

\section{Hypothyroidism and muscle disease}

The relationship between hypothyroidism and muscle disease is known since 19 th century but it is precisely documented ever since 60s (Wilson et al., 1959; Fessel et al, 1968; Golding et al.,1970). In 70s hypothyroid-rheumatic diseases were also described which were defined having symptoms as muscle pain. Muscle pain and stiffness, arthralgia, synovial thickening with effusion, osteolytic lesions, hypothyroid myopathy, acroparaesthesiae, pain, cramps, and stiffness of muscles are common symptoms in hypothyroidism, and mild proximal muscle weakness occurs in over a third of patients (Golding et al., 1971). Pseudomyotonia with delayed relaxation of muscle may occur and a prolonged tendon reflex relaxation time is typical. Myoedema, the "mounding phenomenon," may be elicited in some hypothyroid patients on direct percussion of the muscle. A rare association is Hoffman's syndrome, which is characterised by muscle hypertrophy, weakness, and slowness of movement. The differential diagnosis is from other causes of painful, stiff muscles such as polymyalgia rheumatica and polymyositis. The reflex relaxation time is a useful diagnostic test, and the serum thyroid stimulating hormone concentration should be measured when the doctor is in any doubt. Increased serum activities of enzymes of muscle origin, particularly the creatine kinase isoenzyme, are found in hypothyroidism whether or not muscle symptoms are present. Serum myoglobin concentrations are also raised. Electromyographic studies show a reduction in the mean action potential duration and an increase in the number of polyphasic units in over a third of hypothyroid patients with either normal or hypertrophied muscles. Routine histopathological studies show non-specific findings, but histochemical studies have shown atrophy and reduced frequency of type 2 fibres (Taylor et al., 1983).

Muscle fibre type changes in hypothyroid myopathy were studied by serial percutaneous needle biopsy of vastus lateralis before and during treatment with L-thyroxine by Mc Karen et al. A type II fibre atrophy and loss was found, which correlated with the clinical and biochemical evidence of a myopathy. The type II fibre atrophy was corrected by L-thyroxine 
but type II fibre loss was still apparent in severely myopathic patients up to two years after starting treatment (Mc Karen et al.,1975). Hypothyroid myopathy has not only been reported in long standing cases of hypothyroidism.

Adult patients with myopathy associated with acute transient hypothyroidism were also described. Patients presented with severe muscle aches and cramps, stiffness and spasms. Muscle enzymes were markedly elevated and electromyography in one patient showed myopathic features. Histological changes were absent in muscle biopsy, probably because of the short duration of metabolic disturbance. The myopathy subsided promptly when the hypothyroid state was reversed (Kung et al, 1987).

Muscle weakness, aches and cramps, stiffness and delayed tendon jerk relaxation are usual features of hypothyroid myopathy (30-80\%), while muscle hypertrophy, myoedema and wasting are occasionally seen. They evolve gradually over a long period of time (Bhansali et al.,1999). Hypothyroidism should be differentiated from polymyositis (Mace et al., 1980, Cabili et al.,1982).

Hypothyroidism is also a risk factor for statin-induced myopathy (SIM) and even spontaneous myopathy. Muscle aches, cramps, and weakness are the typical clinical features, irrespective of the precipitant (Bar et al., 2007).

Rhabdomyolysis, the most feared and potentially fatal complication of SIM, is also rarely caused by isolated hypothyroidism. When this is seen, it is usually characterized by a moderate rise in creatine phosphokinase (Khaleli et al., 1983). Data from clinical trials show the rate of SIM in the general population to be $0.1 \%$ to $0.2 \%$; the rate of hypothyroid-induced myopathy is unknown. Because of these associations, patients' thyroid status should always be considered before initiating lipid-lowering medications and, for patients receiving statin therapy, thyroid function should be assessed whenever myopathic symptoms or resistance to therapy is noted (Bar et al., 2007).

\section{References}

Ahmed OM, El-Gareib AW, El-bakry AM, et al. Thyroid hormones states and brain development interactions. Int. J. Devl Neuroscience 2008; 147-209.

Anderson GW, Mariash CN. Molecular Aspects of Thyroid Hormone-Regulated Behavior. Hormones, Brain and Behavior 2002; 539-566.

Bar SL, Holmes DT, Frohlich J. Asymptomatic hypothyroidism and statin-induced myopathy. Canadian Family Physician • Le Médecin de famille canadien, 2007; 428-431.

Bhanja S, Chainy GBN. PTU-induced hypothyroidism modulates antioxidant defence status in the developing cerebellum. Int. J. Devl Neuroscience 2010; 251-262.

Bhansali A, Chandran V, Ramesh J, Acute myoedema: an unusual presenting manifestation of hypothyroid myopathy.

Brodtmann A. Hashimoto Encephalopathy and Down Syndrome. Arch Neurol. 2009; 663-666.

Cabili S, Pines A, Kaplinsky N, et al. Hypothyroidism masquerading as polymyositis. Postgraduate Medical Journal,1982; 545-547. 
Calloni GW, Penno CA, Cordova FM et al. Congenital hypothyroidism alters the phosphorylation of ERK1/2 and p38MAPK in the hippocampus of neonatal rats. Developmental Brain Research 2005; 141- 145.

Calza L, Aloe L, Giardinos L. Thyroid Hormone-Induced Plasticity in the adult rat brain. Brain Research Bulletin 1997; 549-557.

Chen S, Yue C, Yaari Y (2005) A transitional period of Ca2_-dependent spike after depolarization and bursting in developing rat CA1 pyramidal cells. J Physiol 567:79-93.

Darbra S, Garau A, Balada F. Perinatal hypothyroidism effects on neuromotor competence, novelty-directed exploratory and anxiety-related behaviour and learning in rats. Behavioural Brain Research 2003; 209.

Dennis MS. Non-Alzheimer Dementias. Review. 2005.

Dezonne RS, Stipursky J, Gomes FCA. Effect of thyroid hormone depletion on cultured murine cerebral cortex astrocytes. Neuroscience Letters 2009; 58-62.

Dong H, Wade M, Williams A et al. Molecular insight into the effects of hypothyroidism on the developing cerebellum. Biochemical and Biophysical Research Communications 2005; 1182-1193.

Desouzo LA, Ladiwala U, Daniel SM et al. Thyroid hormone regulates hippocampal neurogenesis in the adult rat brain. Mol. Cell. Neurosci. 2005; $414-426$.

England Congenital Hypothyroidism Collaborative New. Elementary school performance of children with congenital hypothyroidism. The Journal of Pediatrics 1990; 27-32.

Escobar GM, Obregon MJ, Escobar del Rey F. Maternal thyroid hormones early in pregnancy and fetal brain development. Best Practice \& Research Clinical Endocrinology \& Metabolism 2004; 225-248.

Fessel, W. J. Myopathy of hypothyroidism Ann. rheum. Dig., 1968; 590.

Gilbert ME. Alterations in synaptic transmission and plasticity in area CA1 of adult hippocampus following developmental hypothyroidism. Developmental Brain Research 2004; 11 - 18.

Golding DN. Hypothyroidism presenting with musculoskeletal symptoms. Ann. rheum. Dis., 1970:10-14.

Jansen HJ, Doebe O, Louwerse ES, et al. Status epilepticus caused by a myxoedema Coma. The Netherlands Journal of Medicine 2006; 202-205.

Joffe RT. Hypothalamic-Pituitary-Thyroid Axis . Hormones, Brain and Behavior. Elsevier (second Edition) Volume 5, Pages 2341-2355.

Khaleeli AA, Griffith Dg, Edwards RHT. The clinical presentation of hypothyroid myopathy and its relation to abnormalities in structure and function of skeletal muscle. Clin Endocrinol, 1983; 365.

Kung AWC, Ma JTC, Yu YL, et al.Myopathy in acute hypothyroidism. Postgraduate Medical Journal, 1987; 661-663.

Lai JL, Tai JT, Liu CK et al. A longitudinal study of central and peripheral nerve conduction in hypothyroid rats. Journal of Neurological Sciences 1997; 139-145.

Lai JL, Lin RT, Tai CT et al. The recovery potential of central conduction disorder in hypothyroid rats. Journal of the Neurological Sciences 2000; 113-119. 
Lasley SM, Gilbert ME. Developmental thyroid hormone insufficiency reduces expression of brain-derived neurotrophic factor (BDNF) in adults but not in neonates. Neurotoxicology and Teratology. 2011; 464-472.

Mac Nabb C, O'hare E, Cleary J et al. Congenital hypothyroidism impairs response alternation discrimination behavior. Brain Research 1999; 231-239.

Mace BEW, Mallya RK, Staffhurt JS. Severe myxoedema presenting with chondrocalcinosis and polymyositis. Journal of the Royal Society of Medicine, 1980;887-888.

Magri F, Buonocore M, Oliviero A, et al. Intraepidermal nerve fiber density reduction as a marker of preclinical asymptomatic small-fiber sensory neuropathy in hypothyroid patients. Eur J Endocrinol 2010; 279-284.

Martin J, Tomkin GH, Hutchinson M. Peripheral neuropathy in hypothyroidism - an association with spurious polycythaemia (Gaisbock's syndrome). Journal of the Royal Society of Medicine 1983;187-189.

Mc Keran RO, Slavin G, Andrews M, et al.Muscle fibre type changes in hypothyroid myopathy. J. clin. Path., 1975; 659-663.

Munhoz RP, Teive HA, Troiano AR et al. Parkinson's disease and thyroid dysfunction. Parkinsonism and Related Disorders 2004; 381-383.

Munte TF, Christian L, Otting G. Cognitive changes in short-term hypothyroidism assessed with event-related brain potentials. Psychoneuroendocrinology 2004; 1109-1118.

Nunez C, Celi F, Ng L et al. Multigenic control of thyroid hormone functions in the nervous system. Molecular and Cellular Endocrinology 287 (2008) 1-12

Osterweil D, Syndulko K, Cohen SN, et al. Cognitive function in non-demented older adults with hypothyroidism. J Am Geriatr Soc. 1992; 325-35.

Piosik PA, Van Groenigen M, Baas F. Effect of thyroid hormone deficiency on $\mathrm{RC} 3$ /neurogranin mRNA expression in the prenatal and adult caprine brain. Molecular Brain Research 1996; 227-235.

Plioplys A, Gravel C, Hawkes R. Selective suppression of neurofilament antigen expression in the hypothyroid rat cerebral cortex. Journal of the Neurological Sciences 1986; 53-68.

Portella AJ, Carvalho F, Faustino L et al. Thyroid hormone receptor $\beta$ mutation causes severe impairment of cerebellar development. Molecular and Cellular Neuroscience 2010; 68-77.

Ramadhan A, Schondorf R, Tamilia M. Rhabdomyolysis and peroneal nerve compression associated with thyroid hormone withdrawal in the setting of remnant ablation: a review of the literature. Canadian Society of Endocrinology and Metabolism annual meeting on October 19, 2009 in Montreal,Canada.

Rastogi L, Godbole M, Ray M et al. Reduction in oxidative stress and cell death explains hypothyroidism induced neuroprotection subsequent to ischemia/reperfusion insult. Experimental Neurology 2006; 290-300.

Roberts CG, Ladenson PW. Hypothyroidism (Seminar). Lancet 2004; 363: 793-803.

Rovet JF, Westbrook DL, Ehrlich RM. Neonatal Thyroid Deficiency: Early Temperamental and Cognitive Characteristics. Journal of the American Academy of Child Psychiatry 1984; 10-22. 
Rovet J, Walker W, Bliss B et al. Long-term sequelae of hearing impairment in congenital hypothyroidism. The Journal of Pediatrics 1996; 776-783.

Sala-Roca J, Carbonel M.A.M., Garau A et al. Effects of chronic dysthyroidism on activity and exploration. Physiology \& Behavior 2002; 125- 133.

Salvi M, Spaggiari E, Neri F, et al. The Study of Visual Evoked Potentials in Patients with Thyroid-Associated Ophthalmopathy Identifies Asymptomatic Optic Nerve Involvement. The Journal of Clinical Endocrinology \& Metabolism, 1997 vol. 82; 1027-1030.

Sawin S, Brodish P, Carter C, et al. Development of Cholinergic Neurons in Rat

Brain Regions: Dose-Dependent Effects of Propylthiouracil-Induced Hypothyroidism. Neurotoxicology and Teratology 1998; 627-635.

Sanchez Alonso JL, Jueavas JM, Torres MAV et al. Role of low-voltage-activated calcium current on the firing pattern alterations induced by hypothyroidism in the rat hippocampus. Neuroscience 2010; 993-1005.

Seah A., Lo YL. Ocular Aspects of Hypothyroidism: Neuro-Ophthalmological Dysfunction in Relation to Thyroid Disease and Iodine. Comprehensive Handbook of Iodine. Elsevier. Nutritional, Biochemical, Pathological and Therapeutic Aspects 2009; Ch 112: Pages 1103-1111.

Shirabe T, Tawara S, Terao A, et al. Myxoedematous polyneuropathy: a light and electron microscopic study of the peripheral nerve and muscle. Journal of Neurology, Neurosurgery, and Psychiatry, 1975; 241-247.

Smith JW, Evans AT, Costal B, Smythe JW. Thyroid hormones, brain function and cognition: a brief review. Neuroscience and Biobehavioral Reviews 2002; 45-60.

Stein MA, Weiss RE. Thyroid function tests and neurocognitive functioning in children referred for attention deficit/hyperactivity disorder. Psychoneuroendocrinology 2003; 304-316.

Sui L, Wang F, Li BM. Adult-onset hypothyroidism impairs paired-pulse facilitation and long-term potentiation of the rat dorsal hippocampomedial prefrontal cortex pathway in vivo. Brain Research 2006; 53-60.

Taylor PK, Turnbull DM. Endocrine myopathies. British Medical Journal 1983; 705-708.

Tong H, Chen GH, Liu RY et al. Age-related learning and memory impairments in adultonset hypothyroidism in Kunming mice. Physiology \& Behavior 2007; 290-298.

Vallortigara J, Alfos S, Micheau J et al. T3 administration in adult hypothyroid mice modulates expression of proteins involved in striatal synaptic plasticity and improves motor behavior. Neurobiology of Disease 2008; 378-385.

Vargiu P, Morte B, Manzano J, et al. Thyroid hormone regulation of rhes, a novel Ras homolog gene expressed in the striatum. Molecular Brain Research 2001; 1-8.

Vasconcellos RFR, Pexisoto MC, Oliveira T, et al. Hoffman's syndrome: pseudohypertrophic myopathy as initial manifestation of hypothyroidism: Case report. Arq. Neuro Psiquiatr. 2003.

Weiss RE, Stein MA, Trommer B, et al. Attention-deficit hyperactivity disorder and thyroid function. The Journal of Pediatrics 1993;539-545. 
Weller A, Rozin A, Rigler O, et al. Neurobehavioral development of neonatal rats after inutero hypothyroxinemia: efficacy of prenatal thyroxine treatment. Early Human Development 1996;63-76.

Wilcoxon JS, Nadolsky GJ, Samarut J et al. Behavioral inhibition and impaired spatial learning and memory in hypothyroid mice lacking thyroid hormone receptor. Behavioural Brain Research 2007; 109-116.

Wilson J, Walton J. Some muscular manifestations of hypothyroidism. J. Neurol. Neurosurg. Psychiat., 1959; 320-324.

Zamoner A., Heimfarth L, Pessoa-Pureur R. Congenital hypothyroidism is associated with intermediate filament misregulation, glutamate transporters down-regulation and MAPK activation in developing rat brain. 


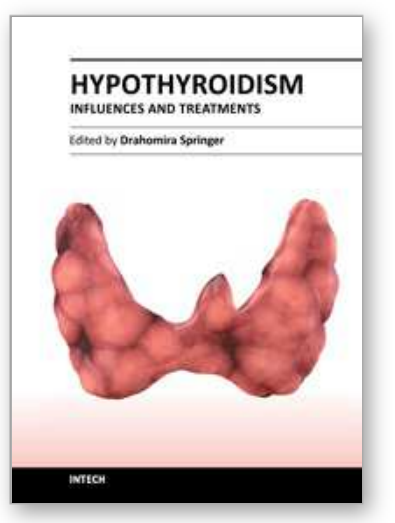

\author{
Hypothyroidism - Influences and Treatments \\ Edited by Dr. Drahomira Springer
}

ISBN 978-953-51-0021-8

Hard cover, 348 pages

Publisher InTech

Published online 08, February, 2012

Published in print edition February, 2012

Hypothyroidism is the most common thyroid disorder and it is significantly more frequent than presented millions of people suffer from this disease without knowing it. People with this condition will have symptoms associated with slow metabolism. Estimates of subclinical hypothyroidism range between 3 to $8 \%$, increasing with age, whereas it more likely affects women than men. About $10 \%$ of women may have some degree of thyroid hormone deficiency. Hypothyroidism may affect lipid metabolism, neurological diseases or other clinical conditions. The book includes studies on advancements in diagnosis, regulation and replacement therapy, thyroid ultrasonography and radioiodine therapy for hypothyroidism. "Hypothyroidism - Influences and Treatments" contains many important specifications, results of scientific studies and innovations for endocrine practice.

\title{
How to reference
}

In order to correctly reference this scholarly work, feel free to copy and paste the following:

Hande Turker, Cuneyt Turker and Nilgun Cengiz (2012). Neurological Complications of Hypothyroidism, Hypothyroidism - Influences and Treatments, Dr. Drahomira Springer (Ed.), ISBN: 978-953-51-0021-8, InTech, Available from: http://www.intechopen.com/books/hypothyroidism-influences-and-treatments/neurologicalcomplications-of-hypothyroidism

\section{INTECH}

open science | open minds

\author{
InTech Europe \\ University Campus STeP Ri \\ Slavka Krautzeka 83/A \\ 51000 Rijeka, Croatia \\ Phone: +385 (51) 770447 \\ Fax: +385 (51) 686166 \\ www.intechopen.com
}

\author{
InTech China \\ Unit 405, Office Block, Hotel Equatorial Shanghai \\ No.65, Yan An Road (West), Shanghai, 200040, China \\ 中国上海市延安西路65号上海国际贵都大饭店办公楼 405 单元 \\ Phone: +86-21-62489820 \\ Fax: $+86-21-62489821$
}


(C) 2012 The Author(s). Licensee IntechOpen. This is an open access article distributed under the terms of the Creative Commons Attribution 3.0 License, which permits unrestricted use, distribution, and reproduction in any medium, provided the original work is properly cited. 